\title{
PERANCANGAN ARENA BOLA BASKET BERTARAF NASIONAL DENGAN PENDEKATAN ARSITEKTUR KONTEMPORER DI KOTA DEPOK
}

\author{
Yossa Leonardo $^{1}$, Atie Ernawati ${ }^{2}$, Arief Nugroho Wibowo ${ }^{3}$ \\ ${ }^{1}$ Universitas Indraprasta PGRI, Program Studi Arsitektur \\ mr.yossaleonardo@gmail.com \\ ${ }^{2}$ Universitas Indraprasta PGRI, Program Studi Arsitektur \\ atie.ernawati@unindra.ac.id \\ ${ }^{3}$ Universitas Indraprasta PGRI, Program Studi Arsitektur \\ Bonic_98@ymail.com
}

\begin{abstract}
One of the bases of the development of the world of basketball in Indonesia is the City of Depok. Not only in big cities like Jakarta, Bandung, Surabaya, Bali, Medan and others, many national basketball players reside in Depok City. Seeing public interest and the development of basketball has reached areas such as Depok, Bogor and others. Therefore, the need for a sports facility that can be utilized and accommodated the need for high public interest in basketball, especially in the city of Depok, and can also accommodate a variety of activities held in the Depok and surrounding areas. In the design of the National Basketball Arena in Depok that uses descriptive analytic methods, the problem will be searched first, after that it will be analyzed in the design process. The design will focus on exploring the forms of structural systems that will be used as a form of structural expression.
\end{abstract}

Keywords: Basketball Arena, Contemporary Architecture, National

\begin{abstract}
Abstrak. Salah satu basis dari perkembangan dunia olahraga bola basket di Indonesia adalah Kota Depok. Tidak hanya di kota-kota besar seperti Jakarta, Bandung, Surabaya, Bali, Medan dan lainlain, banyak pemain basket nasional berdomisili di Kota Depok. Melihat animo masyarakat dan perkembangan olahraga bola basket sudah sampai ke daerah-daerah seperti Depok, Bogor dan lainlain. Oleh karena itu, di butuhkannya suatu fasilitas gedung olahraga yang bisa di manfaatkan dan menampung kebutuhan akan tingginya animo masyarakat pada olahraga bola basket khususnya di Kota Depok, dan juga bisa menampung berbagai kegiatan-kegiatan yang di selenggarakan di kawasan Depok dan sekitarnya. Dalam perancangan Arena Bola Basket Bertaraf Nasional di Kota Depok yang mengunakan metode deskriptif analitik, permasalahan akan di cari telebih dahulu, setelah itu akan di analisis dalam proses perancangan. Perancangan akan berfokus dalam eksplorasi bentuk-bentuk sistem struktur yang akan di gunakan sebagai sebuah bentuk Ekspresi Struktur.
\end{abstract}

Kata Kunci : Arena Bola Basket, Arsitektur Kontemporer, Nasional

\section{PENDAHULUAN}

Bola Basket merupakan cabang olahraga yang sangat di gemari di dunia (selain Sepakbola) dan juga di Indonesia (berada pada urutan ketiga di bawa sepakbola dan bulutangkis). Perkembangan olahraga bola basket ini khususnya di Indonesia, semakin pesat, dengan hadirnya berbagai event-event berskala nasional maupun internasional, dan juga tingginya animo masyarakat yang mengikuti perkembangan olah raga bola basket, mulai dari tingkat pelajar, sampai dengan tingkat professional.

Salah satu basis dari perkembangan dunia olah raga bola basket di Indonesia, adalah Propinsi Jawa Barat yaitu Kota Depok. Tidak hanya di kota-kota besar seperti Jakarta, Surabaya, Malang, Kalimantan dan Kota besar lainnya, animo masyarakat dan perkembangan olahraga bola basket sudah sampai ke daerah-daerah seperti Kota Depok. Sebagai indikatornya, banyak pemainpemain dan atlit basket yang berasal dari daerah Depok yang mampu berprestasi di tingkat propinsi maupun tingkat nasional.

Perkembangan bola basket khususnya di kawasan Depok, juga di tunjang dengan keberadaan pelajar SLTP dan SLTA se Kota Depok yang memilih bola basket sebagai kegiatan esktra kurikuler. Bahkan beberapa tahun lalu, di Kota Depok pernah ada 10 klub bola basket. Tapi kemudian klub-klub itu mati suri bahkan ada yang 
pindah ke Jakarta. Kesepuluh klub basket yang pernah ada di Depok itu adalah Gede, NBC, Depok Citi, Merbuk, DBT, Laser club, Portal, Buanatama, Bhegoest dan terakhir ada Scorpio. NBC, sejak 1 Agustus 2016 lalu aktif kembali dan sudah terdaftar di Perbasi Depok. Sejak 11 September lalu NBC aktif latihan di lapangan basket KONI. Sedangkan Gede dan Buanatama aktif latihan di Jakarta. karena tidak ada lapangan bola basket yang memadai di Depok. Selain itu, banyak juga anak - anak Depok yang bermain ke Jakarta dan Bogor.

Satu-satunya lapangan basket yang ada di Depok adalah milik pemerintah hanya lapangan basket KONI di Kompleks KONI yang berada di jalan Gelatik Raya, Pancoran Mas, Kota Depok. Lapangaan terbuka itu bersebelahan dengan lapangan tenis yang tidak nyaman jika dipakai pada waktu bersamaan. Jika di adakan pertandingan atau event-event bola basket masalah cuaca jadi faktor kendala utamanya mengingat lapangan ini berada di luar dan terbuka.

Ketua Pelaksana Liga Basket Satu Aksi, Dendy Saputra mengatakan, pihaknya menggelar Liga Basket Satu Aksi karena ingin melihat potensi atlet basket di Kota Depok. Tak hanya itu, dengan diselenggarakan kompetisi itu semua klub basket di Depok dapat saling bersilaturahmi. Dikatakan Dendy, dalam liga tersebut khusus untuk klub yang berdomisili di Kota Depok. Sedangkan untuk kategorinya dibagi berdasarkan usia. Diantaranya kelompok umur (KU) 12 tahun putra putri, KU 14 tahun putra putri, KU 16 tahun putra putri, KU 18 tahun putra putri, dan ada juga divisi putra putri yang berusia di bawah 35 tahun Kesembilan klub basket yang ada di Kota Depok sudah mendaftar untuk ikut serta di Liga Basket Satu Aksi yakni Kartika Raya, Gede, Elite Skill, Scorpio, Level Up, Joker Basket Ball, Royal Abrea, Dba dan Finix,

Dirinya menambahkan, dengan semakin banyaknya pertandingan diharapkan dapat mendorong hadirnya atlet-atlet baru, sehingga, kedepan Kota Depok memiliki segudang atlet dapat membawa nama kota ini pada ajang nasional hingga intenasional. Sudah 10 tahun tidak ada liga antar klub basket, jadi ini adalah sebuah terobosan untuk perkembangan dunia basket di Kota Depok," (sumber:www.depok.go.id)

Adhi Pratama, pebasket nasional peraih medali perak SEA Games 2015 yang juga center dari klub juara Liga Bola Basket Indonesia (IBL) 2017 Pelita Jaya, bersiap-siap dari mess klubnya di kawasan Kuningan, Jakarta Pusat, untuk pulang ke Depok. Begitu pula dengan Audy Bagastyo Arizanugra (Ega), point guard Satria Muda Pertamina Jakarta --klub IBL lainnya--, yang berangkat dari markas klubnya di Kelapa Gading, Jakarta Utara, menuju Depok. Sama seperti Adhi dan Ega, turut meluncur Airlangga Sabara, pebasket IBL lainnya dari klub Hangtuah Sumsel.

Ketiga pebasket yang berlaga di liga profesional tersebut merupakan warga Depok. Mereka prihatin dengan fasilitas olahraga di kota domisili mereka, khususnya untuk cabang olahraga bola basket. "Depok adalah kota yang dekat dengan Jakarta, tapi fasilitas olahraga di kota ini sangat memprihatinkan," tutur Adhi, (sumber:https://olahraga.kompas.com/2017/08/0 2).

Oleh karena itu, di butuhkannya suatu fasilitas gedung olahraga basket yang bisa di manfaatkan dan menampung kebutuhan akan tingginya animo masyarakat pada olah raga bola basket di Propinsi Jawa Barat khususnya di Kota Depok sekitarnya.

Standar Nasional adalah standar yang dikembangkan oleh badan standardisasi Nasional untuk digunakan di seluruh dunia. Standar ini dapat digunakan langsung atau disesuaikan dengan kondisi Negara setempat. Adopsi standar internasional suatu Negara dapat menghasilkan standar nasional yang setara dan secara substansial mirip dengan standar Nasional yang dijadikan sumber.

Sesuai dengan standar yang telah ditetapkan oleh NBA atau FIBA selaku organisasi tertinggi dunia yang mengatur seluruh persyaratan dalam permainan atau kompetisi bola basket di Dunia, bola basket harus dilakukan di dalam ruangan, dan dilihat dari pengertian bola basket itu sendiri yang berarti olahraga dalam ruangan, maka olahraga basket ini merupakan jenis olahraga dalam ruangan yang membutuhkan gedung olahraga tertututp sebagai prasarana kegiatannya. 
Menurut standar yang telah ditetapkan oleh Peraturan Menteri Pemuda dan Olahraga Republik Indonesia Nomor 8 Tahun 2018 Tentang Standar Prasarana Olahraga Berupa Bangunan Gedung Olahraga serta bekerjasama dengan Peraturan Menteri Pekerjaan Umum dan Perumahan Nomor 14/PRT/M/2017 tentang Persyaratan Kemudahan Bangunan Gedung.

Tabel 1. Tipologi dan Klasifikasi Gedung Olahraga

\begin{tabular}{|c|c|c|c|c|}
\hline \multirow{2}{*}{$\begin{array}{c}\text { Tipe } \\
\text { Gudung } \\
\text { Olahraga }\end{array}$} & \multirow{2}{*}{$\begin{array}{c}\text { Cabang } \\
\text { Olahraga }\end{array}$} & \begin{tabular}{c} 
Pertandingan \\
Nasional / \\
\cline { 3 - 5 }
\end{tabular} & $\begin{array}{c}\text { Pertandingan } \\
\text { Lokal }\end{array}$ & Latihan \\
\hline Tipe A & Bola Basket & 1 Buah & 1 Buah & 2 Buah \\
\hline Tipe B & Bola Basket & 1 Buah & 1 buah & 1 Buah \\
\hline Tipe C & Bola Basket & - & - & 1 Buah \\
\hline
\end{tabular}

Tabel 2. Ukuran Gedung Olahraga (dalam satuan meter)

\begin{tabular}{|c|c|c|c|c|}
\hline Tipe GOR & $\begin{array}{c}\text { Panjang } \\
\text { Termasuk } \\
\text { Zona Bebas }\end{array}$ & $\begin{array}{c}\text { Lebar } \\
\text { Termasuk } \\
\text { Zona Bebas }\end{array}$ & $\begin{array}{c}\text { Tinggi } \\
\text { Langit-langit } \\
\text { Area } \\
\text { Permainan }\end{array}$ & $\begin{array}{c}\text { Tinggi } \\
\text { Langit-langit } \\
\text { Zona Bebas }\end{array}$ \\
\hline Tipe A & 50 & 40 & 15 & 5,50 \\
\hline Tipe B & 40 & 25 & 12,5 & 5,50 \\
\hline Tipe C & 30 & 20 & 9 & 5,50 \\
\hline
\end{tabular}

Tabel 3. Kapasitas Tempat Duduk Gedung Olahraga

\begin{tabular}{|c|c|c|}
\hline Tipe GOR & Kapasitas GOR & $\begin{array}{c}\text { Jumlah Tempat Duduk } \\
\text { Penonton }\end{array}$ \\
\hline Tipe A & Besar & Minimum 3.000 \\
\hline Tipe B & Sedang & $1.000-3.000$ \\
\hline Tipe C & Kecil & Maksimum 1.000 \\
\hline
\end{tabular}

\section{Fungsi dan Kebutuhan Ruang Yang Ingin Dicapai}

Arena Basket di Kota Depok ini dirancang secara khusus untuk kegiatan olahraga bola basket saja yang memiliki fasilitas lengkap untuk bermain, bertanding, pelatihan, pembinaan dan sebagai tempat olahraga masyarakat. Untuk mendukung perkembangan prestasi basket Indonesia, maka akan dirancang arena basket yang bertaraf Nasional yang dilengkapi dengan fasilitas-fasilitas yang memadai.

Dalam perancangan Arena Basket di Kota Depok, kapasitas lapangan yang akan dirancang nantinya berjumlah 1 lapangan utama dan 2 lapangan multicourt dengan kapasitas penonton 3000-5000 orang yang akan dibagi menjadi beberapa kelas, yaitu kelas umum, kelas VIP dan tribun dilengkapi dengan lavatory.

\section{METODOLOGI}

Sebagai pendekatan perancangan Arena Basket di Kota Depok, ada beberapa aspek pendekatan, yaitu

\section{Tema Sportif Dalam Perancangan}

Secara umum, sportif mengacu pada kebajikan seperti kejujuran, keberanian pengendalian diri, dan ketekunan, dan telah dikaitkan dengan konsep-konsep interpersonal memperlakukan orang lain dan diperlakukan secara wajar, mempertahankan kontrol diri jika berhadapan dengan orang lain, dan menghormati otoritas dan lawan.

a. Adil

Tidak ada yang berat sebelah, sisi satu dengan sisi yang lain akan seimbang kedudukannya tidak ada yang dilebihkan atau dukurangi. Sehingga bangunan nantinya memiliki komposisi yang sama ratanya di dalam site lahan.

b. Jujur

Sumber dari sikap sportif adalah kejujuran, dalam bangunan arsitektur dapat diaplikasikan ke dalam obyek rancang dengan cara memperlihatkan bentuk struktur ataupun pemakaian material yang digunakan. Struktur dapat diekspos dengan kolom-kolom yang besar yang diperlihatkan di bangunan. Konstruksi atap rangka bidang dengan material baja ringan dapat diexpos untuk memperkuat makna jujur dari dalam bangunan itu sendiri. 


\section{c. Transparan}

Salah satu karakter sportif yaitu transparan/ terbuka yang bermakna bahwa seorang mampu menerima masukan dari orang lain dengan baik. Namun dalam arsitektural, pendekatan tema ini lebih bersifat bentuk tampilan, sehingga desain objek rancang kelak memiliki banyak bangunan yang lebih bersifat terbuka dan banyak menggunakan material yang tembus pandang.

\section{d. Gagah}

Kesan gagah yang akan diberikan karena mampu menunjukan sikap yang sportif sehingga bangunan nantinya terlihat kokoh, kuat, meskipun tidak menggunakan material-material yang terlihat berat tapi terlihat sangat kokoh untuk dipandang oleh mata. Kolom yang diekspos pada bangunan Arena Basket ini memberikan kesan gagah dengan menopang atap arena tersebut. Bentukan atap Arena yang didesain miring tersebut memberikan kesan gagah tersendiri pada bangunan nantinya.

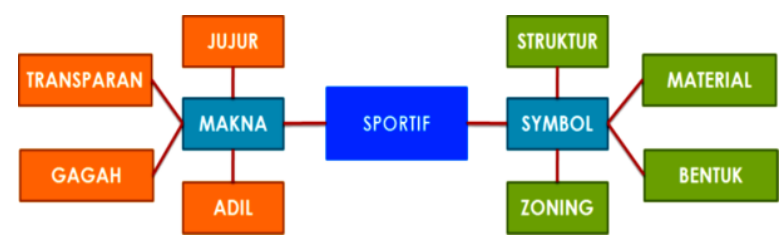

Gambar 1. Diagram Penjabaran Tema Sportif

2. Pengumpulan dan Pengolahan Data

Merupakan kumpulan dari data-data yang berguna bagi perencanaan dan perancangan seperti :

a. Data Primer, berupa survei lapangan, wawancara dan dokumentasi.

b. Data Sekunder, berupa studi literatur dan studi komparasi terhadap obyek.
3. Perumusan Gagasan

Tahap perumusan gagasan ini merupakan proses berpikir secara berurutan dan sistematis, sebagai berikut: Pencarian ide dengan memperhatikan isu yang berkembang saat ini, melakukan observasi terhadap teknologi bangunan baik itu sistem struktur, bahan bangunan, dan lain-lain.

\section{Sintesa}

Data yang telah di analisa akan menghasilkan sintesa berupa konsep - konsep desain yang merupakan upaya pemecahan permasalahan dalam rangka menetapkan konsep perancangan untuk menghasilkan keputusan perancangan.

5. Eksplorasi Desain

Eksplorasi yang dilakukan dalam desain antara lain meliputi :

a. Eksplorasi Ruang (sistem), aspek-aspek yang dieksplorasi meliputi kebutuhan ruang, luasan ruang, hubungan, dan pencapaian ruang.

b. Eksplorasi Tapak dan Lingkungan Ruang Luar, aspek-aspek yang dieksplorasi meliputi lokasi tapak, batas dan ukuran tapak, pencapaian, sirkulasi pada tapak, potensi tapak, orientasi masa, pola tata masa, tautan, dan penataan/perancangan ruang luar (landscaping).

6. Pembahasan Hasil Desain

Merupakan hasil desain dari keseluruhan proses pra-desain yang kemudian dituangkan dalam bentuk gambar-gambar skematik desain. 
HASIL DAN PEMBAHASAN

Sistem Struktur Bangunan

1. Pondasi (sub struktur)

Dalam rancangan desain Depok Arena Basketball disini mengunakan pondasi jenis Bore Pile yang memiliki fungsi untuk memikul atau menahan beban yang dimiliki oleh bangunan lalu kemudian disalurkan kedalam tanah, dan untuk pondasi nya menggunakan footplate.

2. Kerangka Bangunan (middle structure) Kerangka bangunan atau middle structure adalah sistem struktur yang berada di tengahtengah antara sub structure dan upper structure. Fungsi dari kerangka bangunan ini adalah menyalurkan beban yang diberikan dari atap menuju ke pondasi. Pada area pertandingan indoor akan menggunakan sistem rigid frame dengan material beton bertulang, sistem ini mampu menahan gaya pada arah vertikal maupun horizontal. Rigid frame pada umumnya berbentuk simetris dan teratur yang dihubungkan dengan suatu bidang dengan menggunakan sambungan kaku.

\section{Struktur Atap (upper stucture)}

Berdasarkan pertimbangan yang dilakukan sebelumnya, maka struktur atap yang dipakai pada Arena Depok Basketball ini adalah Struktur Space Frame. Hal ini di karenakan ruang lapangan indoor membutuhkan ruang gerak yang besar sehingga struktur Space Frame sangat tepat untuk ruang ini.

\section{Transformasi Bentuk}

Bangunan ini merupakan bangunan olahraga yang dapat di akses oleh umum sehingga bisa jadikan ruang publik. Karena pertimbangan banyak pengunjung yang nantinya menonton event atau sebuah pertandingan basket. Maka, direncanakanlah sebuah arena basket dengan bentuk persegi panjang yang bisa memuat penonton malalui tribun yang cukup dengan penggunaan lahan yang lebih efisien. Penggunaan bentuk persegi panjang sebagai bentuk dasar dari hamper keseluruhan desain dikarenakan bentuk persegi menunjukkan suatu kejujuran dan stabilitas. Persegi merupakan bentuk umum yang sering di gunakan karena bentuk persegi memberikan sesuatu kedadamaian, suatu kesesuaian, keamanan dan kesetaraan sehingga memberikan kesan sederhana bagi sebuah bangunan publik.
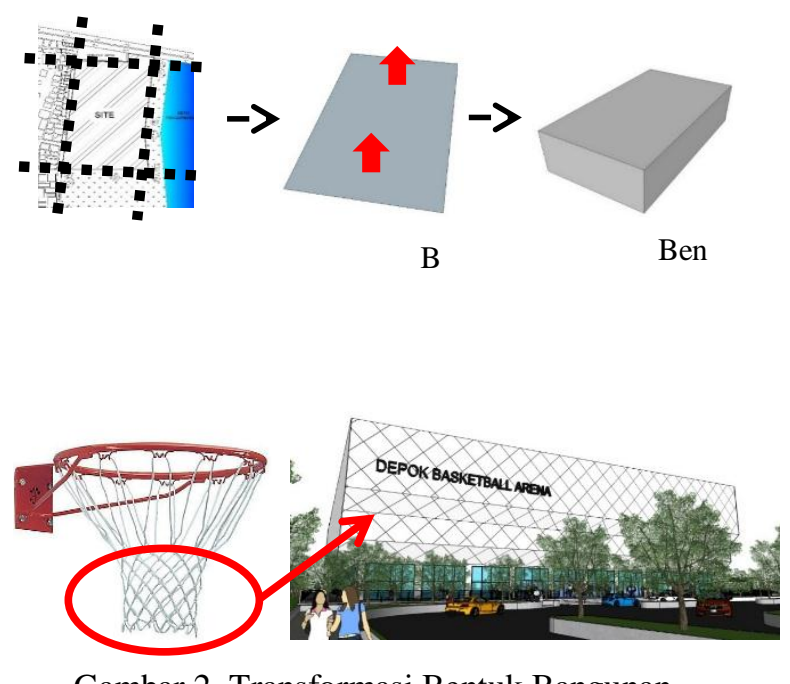

Gambar 2. Transformasi Bentuk Bangunan

Gambar 3. Adaptasi Fasade Bangunan

Salah satu ciri arsitektur kontemporer adalah tampilan fasad yang menarik serta eksplorasi bentuk lansekap. Fasad yang akan ditonjolkan pada Depok Basketball Arena ini yaitu pada penggunaan material Aluminium Composite Panel (ACP) yang di pasang diagonal agar menyerupai jaring basket. Material fasad lainnya yaitu kaca tempered dan expose kerangka aluminium sebagai kusennya, hal ini dipilih agar menimbulkan kesan lebih luas dan elegan, serta memanfaatkan potensi matahari sebagai cahaya alami secara maksimal.

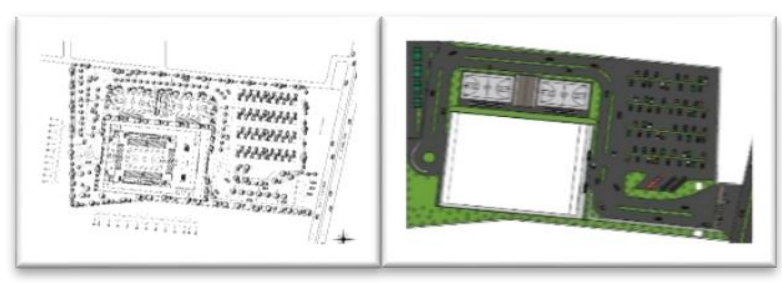



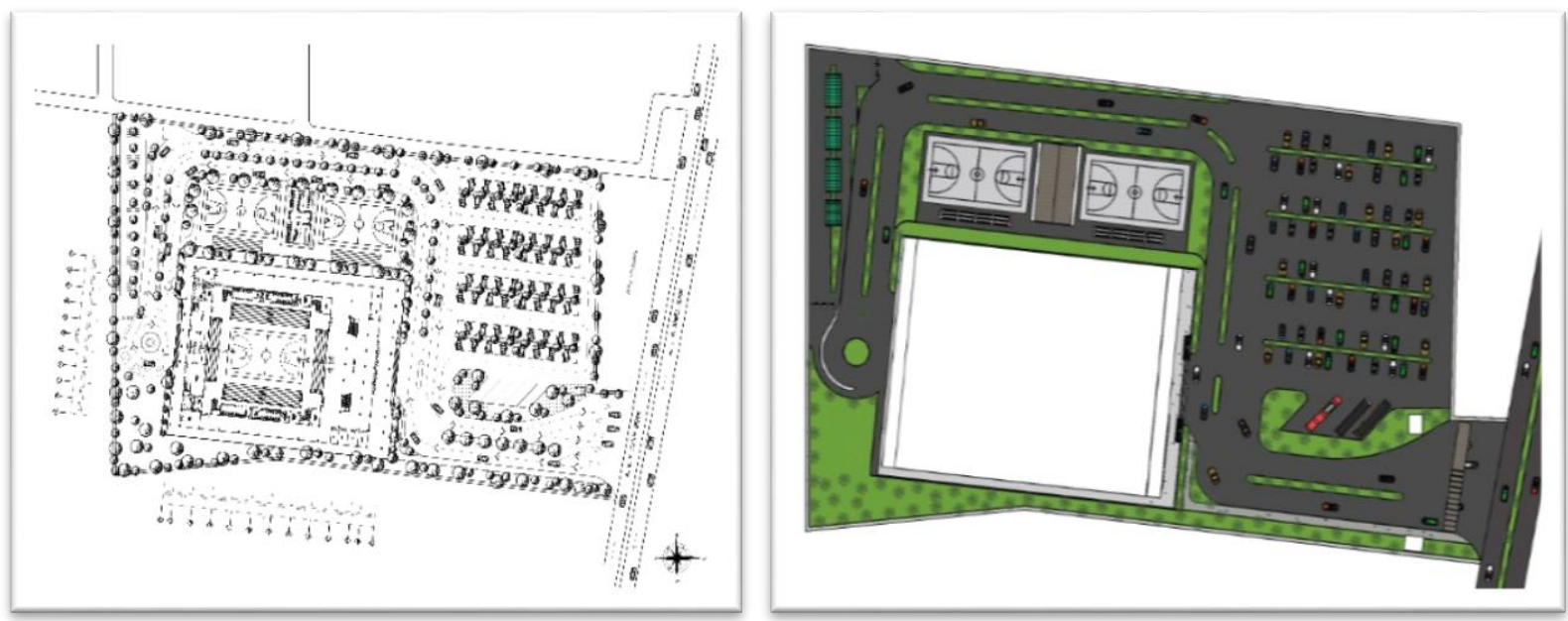

\section{Gambar 4. Site Plan dan Layout}
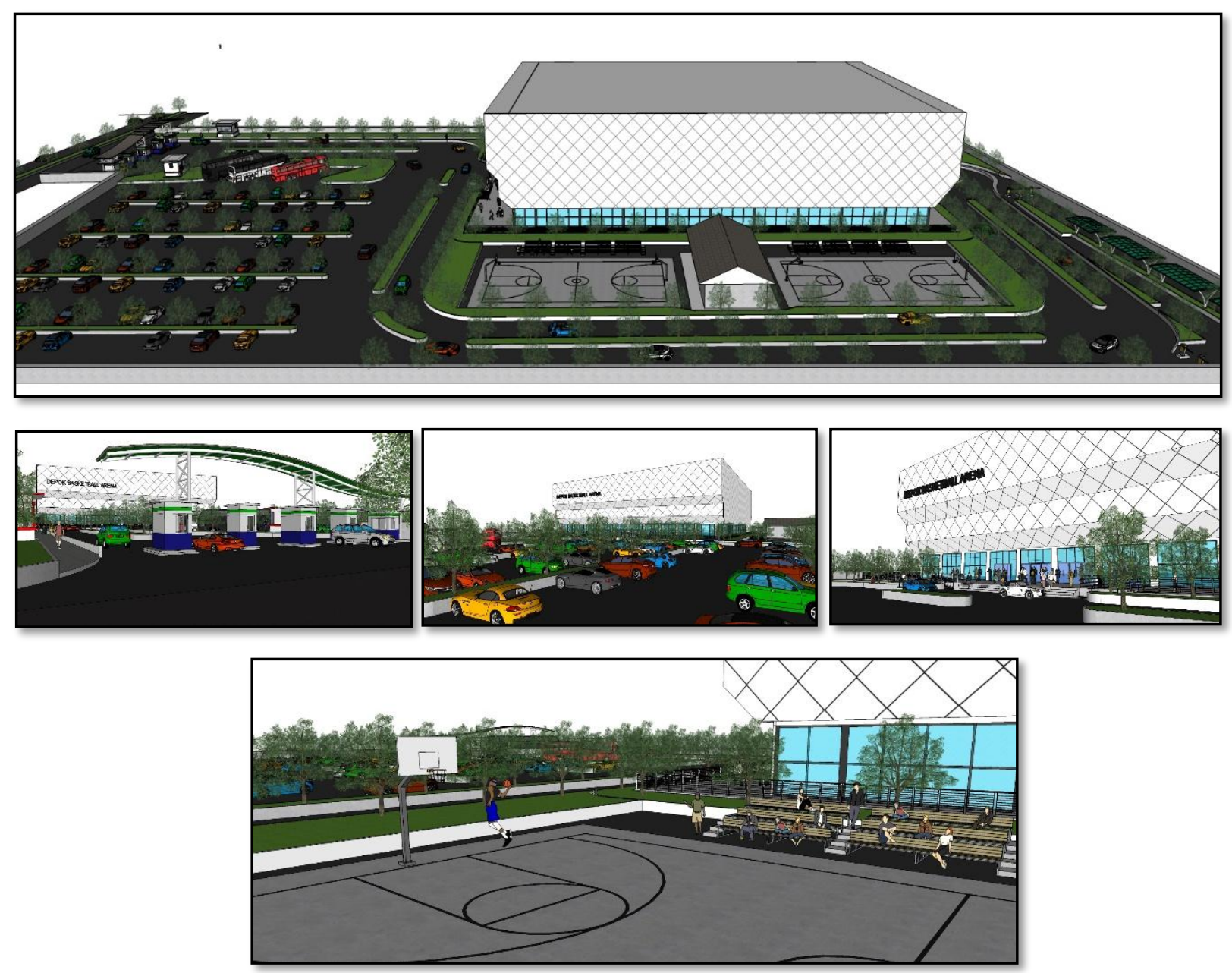


\section{PENUTUP}

\section{Simpulan}

Dari studi dan analisa yang telah dilakukan dalam perancangan Arena Bola Basket di Kota Depok ini dapat diambil kesimpulan sebagai berikut:

1. Depok Basketball Arena ini didesain untuk memenuhi kebutuhan GOR berstandar nasional, serta solusi dari keterbatasan sarana olahraga yang memadai khususnya olahraga basket di kota Depok.

2. Depok Arena Bola Basket dapat digunakan untuk menyelenggarakan event-event besar dan pusat pelatihan, serta tempat sharing hal mengenai basket.

3. Bentuk fasade bangunan di desain dengan mengembangkan unsur persegi agar terkesan lebih sederhana untuk sebuah bangunan publik, serta permainan bentuk fasad diharapkan dapat menimbulkan fantasi tersendiri kepada masyarakat yang berada di dalam maupun luar bangunan.
DAFTAR PUSTAKA

FIBA, 2012. Rules. United States: s.n

PERBASI, 2010. Sejarah Bola Basket Indonesia. Jakarta: s.n.

D.K. Ching, Francis. Arsitektur: Bentuk Ruang dan Susunannya, Erlangga, Jakarta

Neufert, Ernst. Data Arsitek. Jilid 1, Erlangga, Jakarta

https://edoc.site/42peta-rtrw-2012-2032-depokpdf-free.html. Diakses Tanggal 10 September 2018

\section{Lembaga Pemerintah}

PERMENPORA, S. K. No 8 (2018) Standar Prasarana Olahraga Berupa Bangunan Gedung Olahraga. Jakarta : Kantor MENPORA

PERDA KOTA DEPOK No 1 (2015) Rencana Tata Ruang Wilayah Kota Depok Tahun 2012 - 2032. Depok. Jawa Barat 